\title{
Kinetic Study of the Thermal Decomposition for Mixed Municipal Solid Waste Using Thermogravimetric Analysis
}

\author{
Nzioka Antony Mutua ${ }^{1}$, Alunda Benard Ouma ${ }^{2}$, Odero Shirley Atieno ${ }^{3}$ \\ ${ }^{1}$ Department of Environmental and Energy Engineering, Kyungpook National University, Republic of Korea \\ ${ }^{2}$ Department of Mining and Mineral Processing Engineering, Taita Taveta University, Kenya \\ ${ }^{3}$ World Food Programme, Kenya
}

\begin{tabular}{l} 
Article Info \\
\hline Article history: \\
Received May $30^{\text {th }}, 2017$ \\
Revised Aug $20^{\text {th }}, 2017$ \\
Accepted Oct $18^{\text {th }}, 2017$ \\
\hline Keyword: \\
Thermal decomposition \\
Temperature \\
Municipal solid waste \\
ANOVA \\
Composition \\
Activation Energy
\end{tabular}

\section{Corresponding Author:}

Nzioka Antony Mutua

Department of Environmental and Energy Engineering,

Kyungpook National University,

Daehak-ro 80, Buk-gu, College of Engineering, Daegu, 41566, Republic of Korea

Email: manymutua@knu.ac.kr

\section{Background}

There are different solutions proposed by researchers seeking to reduce the adverse effects of accumulating municipal solid wastes (MSW) in countries with developing and emerging economies. One of the perspective solutions is thermal conversion processes which may such processes such as pyrolysis, wasteto-energy, aerobic/anaerobic conversion processes among others[1]-[4]. Previous research showed that recycling and conversion of MSW with high moisture content to refuse derived fuel is feasible and may require minimal treatment [1],[5],[6].

Thermal decomposition process may provide sufficient information so as to understand the thermal conversion process. Thermogravimetric analysis is one of the perspective methods of studying the thermal decomposition process of any material including MSW. Some researchers have presented valuable data related to the thermogravimetric analysis of the MSW [7]-[9]. Research presented in the publications mentioned above focussed on thekinetic characteristics of the components or a combination of components in the MSW. It is, in our opinion, of utmost importance to study the sample material (i.e. MSW) with all the components combined. 
Therefore, the objectives of this research are to study the thermal decomposition of MSW, derive the kinetic characteristics as well as study the effect of changes in the composition of MSW on the kineticcharacteristics of the thermaldecomposition process.

\section{Materials and methods}

\subsection{Materials}

Sample MSW consisted of plant wastes, shredded plastics and paper and wood chips. In this research, we used combustible materials and excluded all possible inert materials (glass, soil, metals etc.) We prepared two sets of samples as shown in Table 1 based on other references[5], [10], [11]. The particle size of sample MSW was $<20 \mathrm{~mm}$ recommended by Athanaopolous [12], and

reference [13]providedmathematical formulation for determining theparticle size of our sample MSW. The sample MSW used in this research was prepared on as received basis. We conducted this experimental study based on the workflow presented in Figure 1.

We prepared sample MSW and used approximately $200 \mathrm{~g}$. We dried the sample MSW at a temperature of $80^{\circ} \mathrm{C}$ for 24 hours. We used ASTM E955 - 88 standards to determine ash content on "dry material"basis [14].

Table 1. Composition of the sample MSW used in the experimental study

\section{Mixing proportion, (\% weight basis) for "as received" MSW}

\begin{tabular}{|c|c|c|}
\hline Component & Set 1 & Set 2 \\
\hline Plant wastes & 73 & 52 \\
\hline Shredded paper & 11 & 21 \\
\hline Shredded plastics & 11 & 21 \\
\hline wood & 5 & 6 \\
\hline \multicolumn{3}{|c|}{ Proximate analysis } \\
\hline Ash content, $(\%)$ & $6 c>12$ & $10 \backsim 12$ \\
\hline *Moisture content, $(\%)$ & $55 \propto 56$ & $35 \operatorname{cs} 38$ \\
\hline *Bulk Density, $\left(\mathrm{kg} / \mathrm{m}^{3}\right)$ & $85 \sim 109$ & $60 \sim 576$ \\
\hline
\end{tabular}

\section{Remark:}

Mixing proportion provided in this table is based onprevious research [5]

* . "as received" basis

References [4], [5] provided formula for calculating the bulk density for "as-received" MSW. We calculated the gross calorific values using bomb calorimeter (plain-jacket oxygen bomb-type, Parr Instrument CompanyUSA). Calorific standard (Benzoic acid pellets) used were in accordance with Parr Instrument Company's (USA) specification. We calculated appropriate corrections from the "after-combustion" remains of the bomb calorimeter: these correctionsare specifiedin the analytical equipment's manual.Net calorific values were determined using empirical formulas provided by Ilinykh[15] as well as ASTM E955-88 standards [14]. The formula (1) was suggested by Ilinkh while (2) by ASTM E955 - 88 standards. Calorific values were converted to $\mathrm{MJ} / \mathrm{kg}$ SI unit. The formulas for calculating the net calorific values are shown below:

$$
\begin{aligned}
& Q_{N}=4600-4 A-51.85 X \\
& Q_{N}=\frac{[100-(X+A)] Q_{g}}{100}
\end{aligned}
$$


In the formulasabove, $Q_{g}, Q_{N}$ represent gross and net calorific values respectively (MJ/kg) while variables $A, \mathrm{X}$ represent ash content and moisture content shown in Table 1. We calculated the gross calorific values on "dry material" basis and the net calorific values on "as received" basis.

We analysed the thermal decomposition process using TGA-50 supplied by Shimadzu Scientific (USA) equipped with the thermal analysis workstation (Shimadzu TA-60WS). We reduced the particle size of the sample MSW and prepared pellets using laboratory press machine and a roundshape tablet press $(4 \mathrm{~mm}$ diameter). TGA analysis was conductedup to $900^{\circ} \mathrm{C}(1173 \mathrm{~K})$ for four different temperature rates $(5,10,20$ and $50 \mathrm{~K} / \mathrm{min}$ ) under inert conditions sustained using argon gas (gas flowrate $=10 \mathrm{ml} / \mathrm{min}$ ).

\section{Thermal decomposition theory and calculation}

General formula used to describe reaction kinetics (i.e. thermal decomposition process) can be written as follows [16]:

$$
\frac{d c}{d t}=k(T) f(c)
$$

From the equation above, function $k(T)$ represents the rate constant which conforms with the Arrhenius law. We may express the rate constant as follows:

$$
k(T)=A e^{\frac{-E}{R T}}
$$

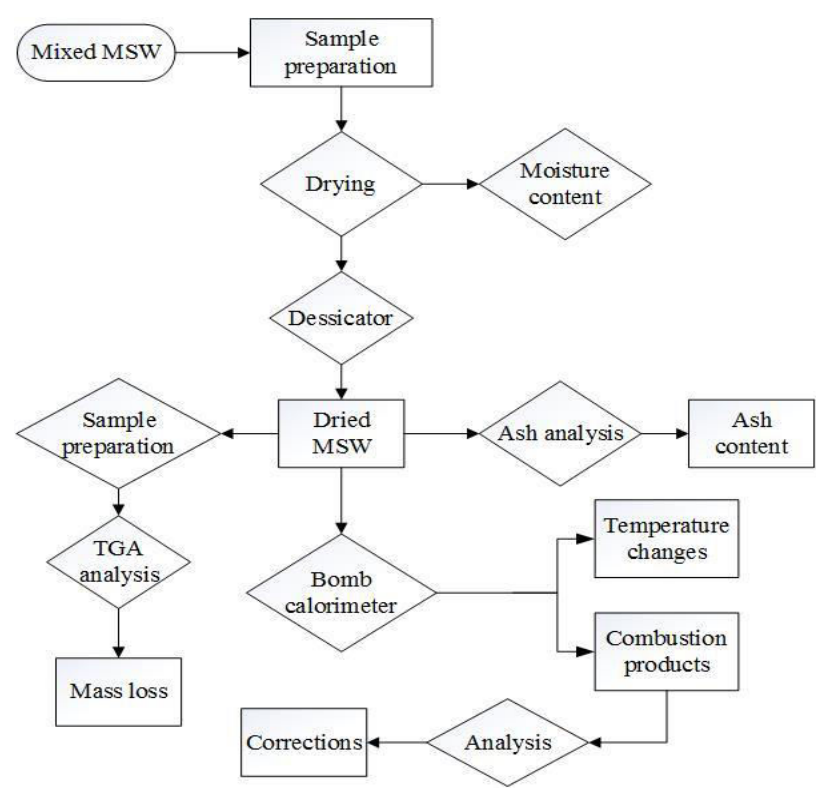

Figure 1. Experimental analysis workflow

where variable $E$ represent the activationenergy $(\mathrm{kJ} / \mathrm{mol}), R$ - universal gas constant $(\mathrm{j} / \mathrm{mol} \mathrm{K}), A$ - preexponential factor (/min)and $T$ - temperature (K). We might justify (3) by assuming that the sample MSW would undergo complex decomposition process generating volatile substances and char[16]. Therefore, we may determine the degree of conversion $(c)$ using the following expression[17]: 


$$
c=\frac{m_{t-\text { start }}-m_{t-i}}{m_{t-\text { start }}-m_{t-\text { final }}}
$$

where variables $m_{t-s t a r t}, m_{t-f i n a l}, m_{t-i}$ represent initial, final and mass at the time (i). If we assume that our reaction is first-order $(\mathrm{n}=1)$, then (3) may be rewritten as follows:

$\frac{d c}{d t}=(1-c)^{n} A e^{\frac{-E}{R T}}$

Formula (6) corresponds to isothermal conditions. Thermogravimetric analysis is conducted under nonisothermal conditions whereby the actual temperature is expressed as a function of heating rates. Therefore, we will rewrite (6) to satisfy the non-isothermal conditions as follows [16]:

$$
\frac{d c}{d T}=(1-c)^{n} \frac{A}{\beta} e^{\frac{-E}{R T}}
$$

From the formula above, $\beta$ represents the rate of heating $(\mathrm{K} / \mathrm{min})$ that we will use in thermogravimetric analysis.

In this study, we will use several non-isothermal model equations, namely: Kissinger, Kissinger Akahira - Sunose and Flynn - Wall - Ozawa. The Kissinger model equation can be described as follows[18]:

$$
\ln \left(\frac{\beta}{T_{m}^{2}}\right)=\ln \left(\frac{A R}{E}\right)-\frac{E}{R T_{m}}
$$

From the formula above, variable $T_{m}$ represent the peak temperature $(\mathrm{K})$ where $d m_{t-i} / d t=0$. We may calculate the activation energy by plotting a graph of $\ln \left(\beta / T_{m}^{2}\right)$ versus $1000 / T_{\mathrm{m}}$. The Kissinger - Akahira - Sunose model equation can be expressed as follows:

$$
\ln \left(\frac{\beta}{T_{\alpha(i)}^{2}}\right)=\ln \left(\frac{A_{\alpha(i)} R}{E_{\alpha(i)} g[\alpha(i)]}\right)-\frac{E_{\alpha(i)}}{R T_{\alpha(i)}}
$$

We can calculate the activation energy using model equation (9) mentioned above by plotting a graph of $\ln \left(\beta / T_{\alpha(i)}^{2}\right)$ versus 1000/ $T_{\alpha(i)}$. From formula (9) variable $E_{\alpha(i)}, T_{\alpha(i)}$ represent activation energy and temperature at conversion value $\alpha(i)$ respectively. Santos et al. [17] provided precise formulation and explanation of the integral function $g[\alpha(i)]$. The final model that we will use in our study (Flynn - Wall Ozawa) can be expressed as follows:

$$
\begin{aligned}
& \ln (\beta)=\ln \left(\frac{A_{\alpha(i)} E_{\alpha(i)}}{R g[\alpha(i)]}\right)- \\
& -5.331-1.052 \frac{E_{\alpha(i)}}{R T_{\alpha(i)}}
\end{aligned}
$$


From formula (10) we can determine activation energy from the graphical dependence of $\ln (\beta)$ versus $1000 / T_{\alpha(i)}$. In this experiment, we will analyse the level of variance for our samples (i.e set 1 and 2 ). We will use one-way ANOVA analysis for the activation energy values obtained for all the model equation used. The following conditions were considered for the one-way ANOVA test:

- Levene test of variance

- Actual power analysis

- Tukey range test

- $\quad$ Number of Tests $=5$

\section{Results and discussion}

\subsection{Gross and net calorific value}

Table 2 shows the gross and net calorific values of the mixed MSW. Experimental and empirical results showed that the mixed MSW with low plant wastes content (MSW set 2) had higher calorific value than that with high plant wastes content (i.e. MSW set 1). We obtained these calorific values without including the soil content. Soil, just like many inert compounds, are bound to have an adverse effect the calorific values of MSW since a significant amount of heat may be used in the oxidation /formation of other compounds from the inert substances. Our preliminary analysis coupled with previous research supported our conclusion [19].The net calorific values calculated using the empirical formulas chose did not differ significantly.

Table 2. Calorific values for mixed MSW

Gross calorific values, $\mathrm{MJ} / \mathrm{kg}$

\begin{tabular}{c|cc}
\hline & Set 1 & Set 2 \\
\hline $\mathrm{Q}_{\mathrm{g}}$ & $14.5 \pm 0.5$ & $16.9 \pm 1.2$ \\
\hline & Net calorific values, MJ/kg & \\
\hline Ilinykh (2013) & $6.1 \pm 0.15$ & $10 \pm 0.3$ \\
ASTM E955 (2009) & $5.1 \pm 0.3$ & $8.6 \pm 0.25$ \\
\hline
\end{tabular}

\subsection{Thermal decomposition}

Thermal decomposition process was analyzedfrom the temperature of $300 \mathrm{~K}$ to1073 K. Decomposition reaction showed similar decomposition characteristics for all the temperature rates. Thesedecomposition characteristics were in three stages, namely: dehydration; fast decomposition of high molecular substances such as cellulose, lignin, etc. and subsequent and slow degradation of lower molecular compounds with the formation of char. Dehydration phase ended at a temperaturerange of500 - $568 \mathrm{~K}$ for MSW set 1 and 495 $560 \mathrm{~K}$ for MSW set 2.The second phase characterising the fast degradation process of high molecular compounds ended at a temperature range of $788-872 \mathrm{~K}$ for MSW set 1 . The final stage began from thetemperatures mentioned above till $1173 \mathrm{~K}$. Solid residue for MSW was between $6-10 \%$ for MSW set 1 and $11-12$ for MSW set 2 which corresponds to the values obtained from the proximate analysis. Preliminary analysis indicated that the presence of impurities such as inert substances might lead to the formation of anomalous/irregular decomposition behaviour of the MSW. 

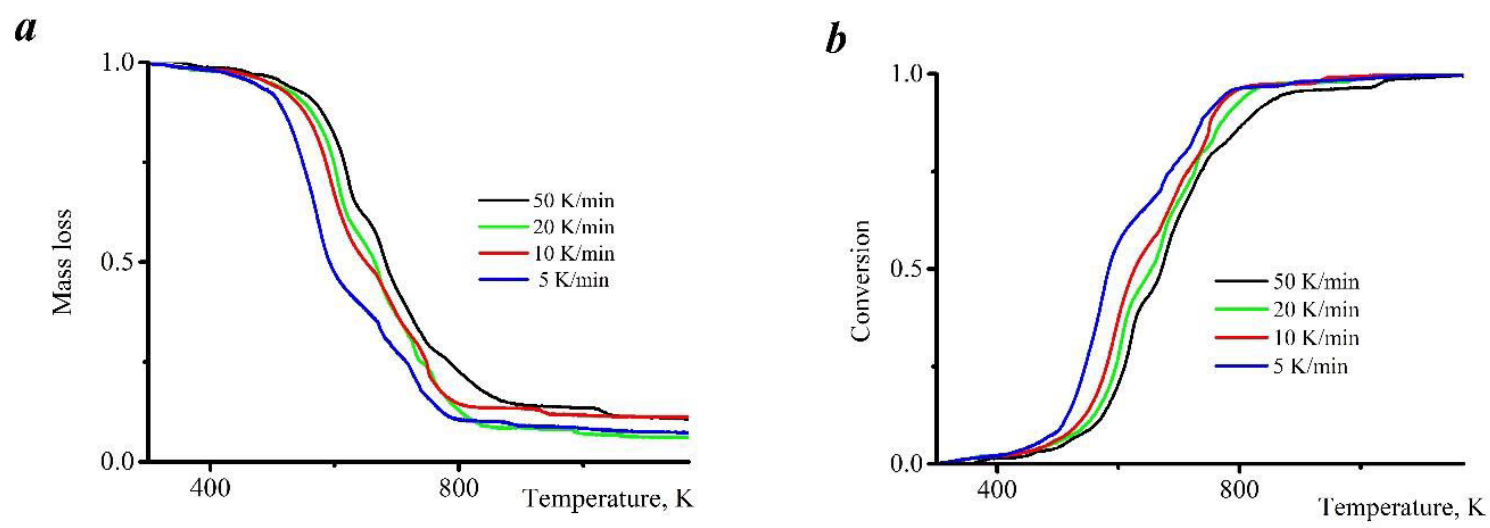

Figure 2. TGA mass loss and conversion curves for MSW set 1. Graph a: TGA mass loss and b: conversion curves.
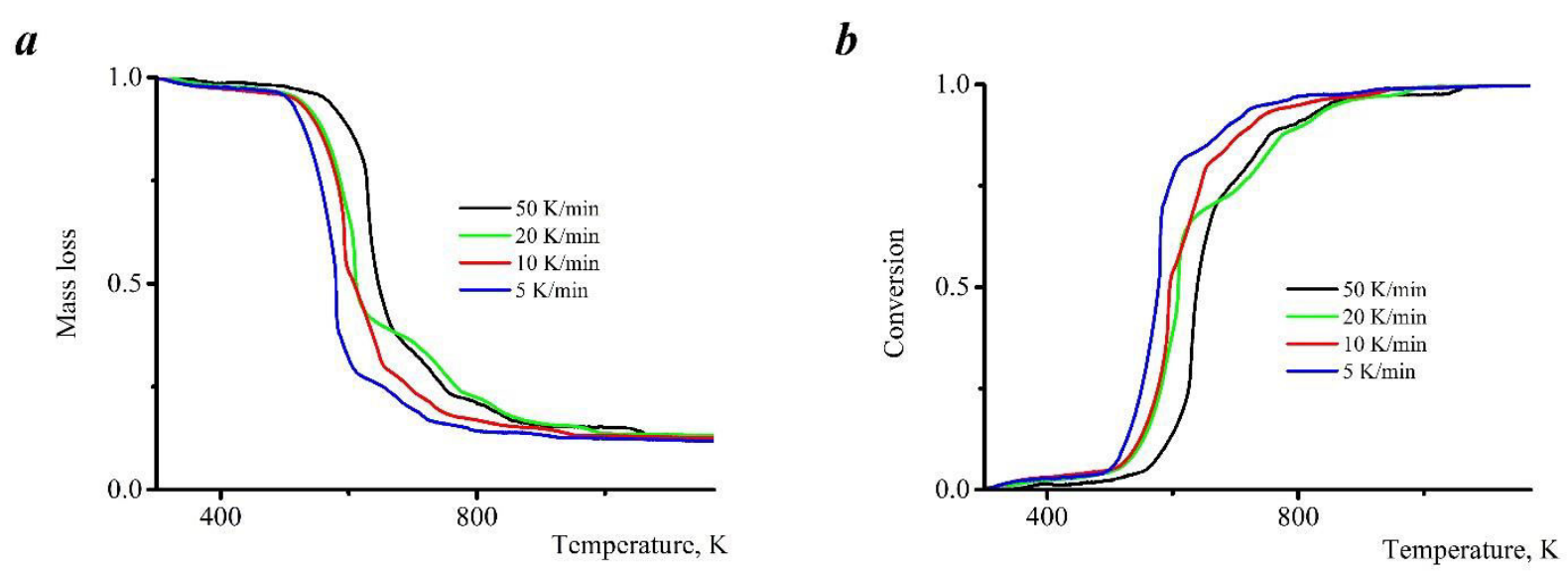

Figure 3. TGA mass loss and conversion curves for MSW set 2:Fig.a - TGA mass loss and b - conversion curves

\subsection{Kinetic study and statistical analysis}

We derived the linear regression equations for conversion values ranging from 0.1 to 0.8 for Kissinger Akahira - Sunose / Flynn - Wall - Ozawa model equations and Kissinger Model equations to determine the activation energy values. From the Kissinger model equation, the activation energy values for MSW set 2 were higher than those of MSW set 1: MSW set 2 had a mean activation value of $122.5 \mathrm{~kJ} / \mathrm{mol}$ while MSW set $1 \mathrm{had} 135.6 \mathrm{~kJ} / \mathrm{mol}$.

From Kissinger - Akahira - Sunose model equation, the activation energy values ranged from $76-90$ $\mathrm{kJ} / \mathrm{mol}$ for MSW set 1 and $78-105 \mathrm{~kJ} / \mathrm{mol}$ for MSW set 2. From the Flynn - Wall - Ozawa model equation, the activation energy values ranged from $75-96 \mathrm{~kJ} / \mathrm{mol}$ for MSW set 1 and $83-109 \mathrm{~kJ} / \mathrm{mol}$ for MSW set 2 . From these two model equation, it is evident that MSW set 2 had theaverageactivation energy greater than MSW set 1 . This resultis in contrast with the values we obtained usingthe Kissinger model equation. 


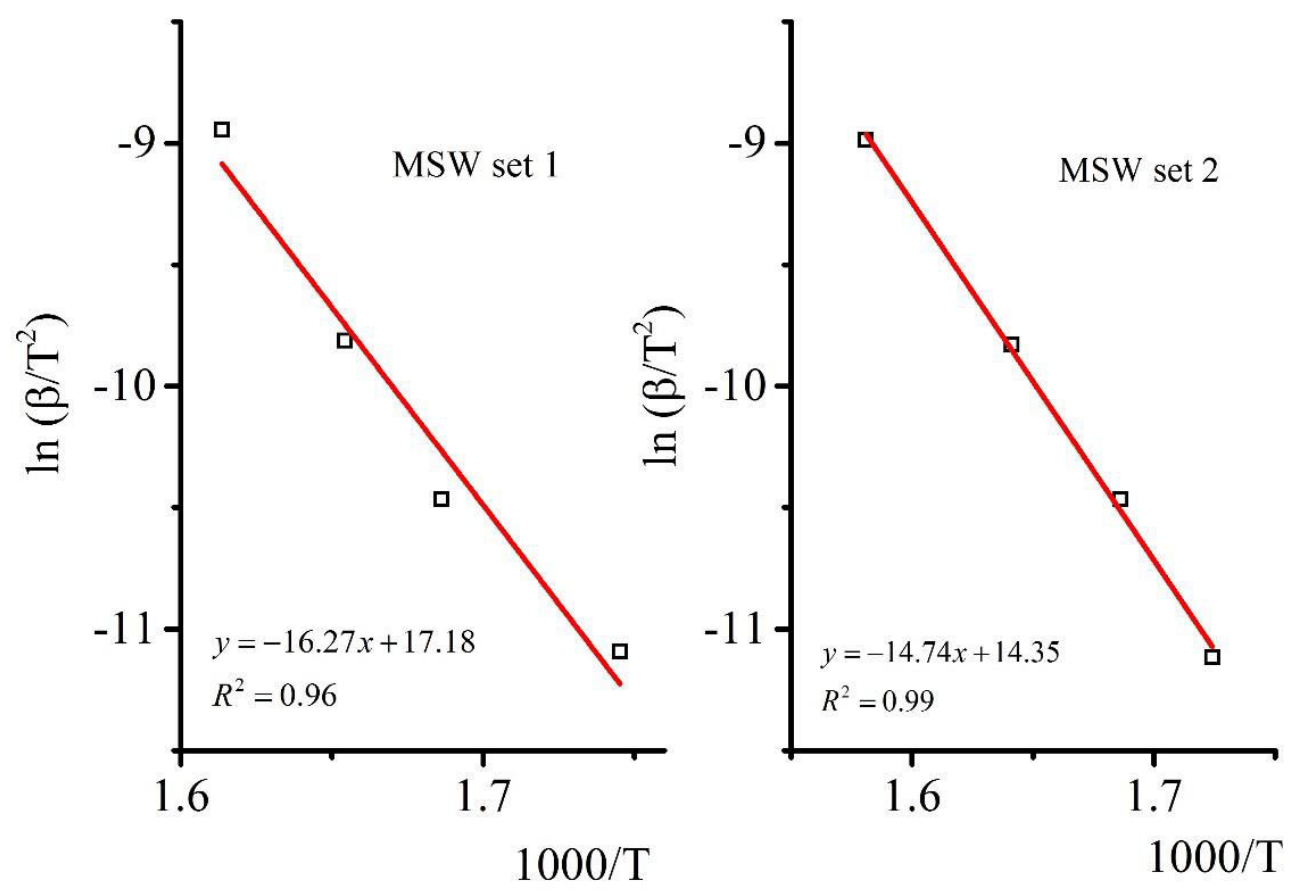

Figure 4. Graphicplots derived using the Kissinger model equation for MSW set 1 and 2

We conducted preliminary thermal decomposition analysis of MSW with inert substances (soil) with the objective of investigating the feasibility of correlating the differences between activation energy values and the organic plant wastes composition. Even thoughwe might correlate such differences with the composition of organic plant wastes in this experimental study, the irregularcharacteristics of the thermal decomposition of MSW+inert substances from our preliminary analysis with MSW did not support our theory.

Table 3. Linear regression equations derived using Kissinger - Akahira - Sunose model equation

\begin{tabular}{|c|l|c|c|l|c|c|}
\hline \multirow{2}{*}{} & \multicolumn{3}{|c|}{ MSW Set 1 } & \multicolumn{2}{c|}{ MSW set 2 } \\
\cline { 2 - 7 } & \multicolumn{1}{|c|}{$\boldsymbol{y}=\boldsymbol{a} \boldsymbol{x}+\boldsymbol{b}$} & $\mathbf{R}^{\mathbf{2}}$ & $\mathbf{E}$ & $\boldsymbol{y}=\boldsymbol{a} \boldsymbol{x}+\boldsymbol{b}$ & $\mathbf{R}^{\mathbf{2}}$ & $\mathbf{E}$ \\
\hline $\mathbf{0 . 1}$ & $y=-10.84 x+10.9$ & 0.95 & 90 & $\mathrm{y}=-9.51 \mathrm{x}+7.58$ & 0.94 & 78.9 \\
\hline $\mathbf{0 . 1 5}$ & $y=-9.95 x+7.97$ & 0.95 & 83 & $\mathrm{y}=-9.25 \mathrm{x}+6.55$ & 0.93 & 76.9 \\
\hline $\mathbf{0 . 2}$ & $y=-9.7 x+7.02$ & 0.92 & 80.6 & $\mathrm{y}=-9.14 \mathrm{x}+5.97$ & 0.93 & 76.1 \\
\hline $\mathbf{0 . 2 5}$ & $y=-9.78 x+6.8$ & 0.93 & 81.4 & $\mathrm{y}=-9.4 \mathrm{x}+6.15$ & 0.93 & 78.2 \\
\hline $\mathbf{0 . 3}$ & $y=-10.26 x+7.34$ & 0.92 & 85.4 & $\mathrm{y}=-10.18 \mathrm{x}+7.28$ & 0.94 & 84.8 \\
\hline $\mathbf{0 . 3 5}$ & $y=-11.06 x+8.44$ & 0.93 & 91.2 & $\mathrm{y}=-10.96 \mathrm{x}+8.43$ & 0.95 & 91.2 \\
\hline $\mathbf{0 . 4}$ & $y=-11 x+8.06$ & 0.91 & 91.5 & $\mathrm{y}=-11.9 \mathrm{x}+9.8$ & 0.97 & 98.9 \\
\hline $\mathbf{0 . 4 5}$ & $y=-8.43 x+3.43$ & 0.93 & 67.9 & $\mathrm{y}=-12.58 \mathrm{x}+10.72$ & 0.99 & 104.3 \\
\hline $\mathbf{0 . 5}$ & $y=-8.42 x+3.14$ & 0.93 & 69.8 & $\mathrm{y}=-12.58 \mathrm{x}+10.72$ & 0.99 & 104.5 \\
\hline $\mathbf{0 . 5 5}$ & $y=-8.3 x+2.62$ & 0.9 & 68.8 & $\mathrm{y}=-12.57 \mathrm{x}+10.6$ & 0.97 & 104.8 \\
\hline $\mathbf{0 . 6}$ & $y=-9.17 x+3.61$ & 0.87 & 76.4 & $\mathrm{y}=-11.2 \mathrm{x}+8.14$ & 0.91 & 92.9 \\
\hline
\end{tabular}


Table 4. Linear regression equations derived using Flynn - Wall - Ozawa model equation

\begin{tabular}{|c|l|c|c|l|c|c|}
\hline \multicolumn{4}{|c|}{ MSW set 1 } & \multicolumn{3}{c|}{ MSW set 2 } \\
\cline { 2 - 8 } & \multicolumn{1}{|c|}{$\boldsymbol{y}=\boldsymbol{a} \boldsymbol{x}+\boldsymbol{b}$} & $\mathbf{R}^{\mathbf{2}}$ & $\mathbf{E}$ & $\boldsymbol{y}=\boldsymbol{a x}+\boldsymbol{b}$ & $\mathbf{R}^{\mathbf{2}}$ & $\mathbf{E}$ \\
\hline $\mathbf{0 . 1}$ & $y=-12.12 x+25.45$ & 0.96 & 95.6 & $y=-10.61 x+22.2$ & 0.96 & 83.6 \\
\hline $\mathbf{0 . 1 5}$ & $y=-11.05 x+25.6$ & 0.93 & 87.5 & $y=-10.4 x+21.23$ & 0.94 & 82.1 \\
\hline $\mathbf{0 . 2}$ & $y=-10.84 x 21.7$ & 0.92 & 85.7 & $y=-10.3 x+20.69$ & 0.96 & 81.6 \\
\hline $\mathbf{0 . 2 5}$ & $y=-10.93 x+21.53$ & 0.92 & 86.5 & $y=-10.58 x+20.9$ & 0.96 & 83.7 \\
\hline $\mathbf{0 . 3}$ & $y=-11.43 x+22.1$ & 0.92 & 90.4 & $y=-11.37 x+22$ & 0.96 & 90 \\
\hline $\mathbf{0 . 3 5}$ & $y=-12.24 x+23.2$ & 0.93 & 96.7 & $y=-12.16 x+23.21$ & 0.97 & 96.2 \\
\hline $\mathbf{0 . 4}$ & $y=-12.2 x+22.86$ & 0.94 & 96.5 & $y=-13.1 x+24.61$ & 0.98 & 103.5 \\
\hline $\mathbf{0 . 4 5}$ & $y=-10.6 x+19.84$ & 0.96 & 83.8 & $y=-13.66 x+25.44$ & 0.99 & 107.6 \\
\hline $\mathbf{0 . 5}$ & $y=-9.67 x+18$ & 0.95 & 76.2 & $y=-13.8 x+25.54$ & 0.99 & 109.4 \\
\hline $\mathbf{0 . 5 5}$ & $y=-9.55 x+17.53$ & 0.91 & 75.2 & $y=-13.8 x+25.4$ & 0.97 & 98 \\
\hline & & & & & & \\
\hline
\end{tabular}

We conductedone-way ANOVA test analysis so as to determine the level of similarity/variance between MSW set 1 and 2. ANOVA test for all the cases and model equations showed significant differences between MSW set2 and MSW set 1

\section{Conclusion}

We investigated the thermal decomposition of MSW, and the following conclusions would be made:

1. Calorific values of MSW set 2 were higher than that of MSW set 1 . We could attribute these differences to the composition of MSW.

2. Net calorific values calculated empirically exhibited some similarity

3. The thermal decomposition process for MSW showed similar decomposition characteristics

4. Activation energy values derived using Kissinger model ranged from $135 \mathrm{~kJ} / \mathrm{mol}$ for MSW set 1 and $122 \mathrm{~kJ} / \mathrm{mol}$ for MSW set 2 .

5. Activation energy using Kissinger - Akahira - Sunose model equation ranged from76 - $90 \mathrm{~kJ} / \mathrm{mol}$ for MSW set 1 and $78-105 \mathrm{~kJ} / \mathrm{mol}$ for MSW set 2. MSW set 2 had an average activation energy value greater than that of MSW set 1

6. Activation energy using Flynn - Wall - Ozawa model equation ranged from $75-96 \mathrm{~kJ} / \mathrm{mol}$ for MSW set 1 and $83-109 \mathrm{~kJ} / \mathrm{mol}$. MSW set 2 had an average activation energy value greater than that of MSW set 1

7. Measurement of variance showed a significant difference in activation energy values.

\section{References}

[1] A. G. Troshin and A. M. Nzioka, "Method of processing unsorted municipal solid waste utilising heat energy from reciprocating grate cooler during the cooling process," Ukraine Patent № 83321 C1, 2013.

[2] L. B. Pavlovich, N. Y. Solovyova, E. D. Pavlovskaya, and V. M. Strakhov, "Using polymer waste in coke production," Cokeand Chemistry, vol. 59, pp. 287-295, Aug. 2016. doi: 10.3103/S1068364X16080068

[3] K. Miezah, K. Obiri-Danso, Z. Kádár, S. Heiske, B. Fei-Baffoe, M. Mensah and A. S. Meyer, "Municipal Solid Waste Management in a Low Income Economy Through Biogas and Bioethanol Production," Waste and Biomass Valorization, vol. 8, pp. 115-127, 2017. doi: 10.1007/s12649-0169566-5

[4] L. F. Diaz, G. M. Savage, L. L. Eggerth and L. Rosenberg, Solid waste management. Paris: Cal. Recovery Inc. and United Nations Environment Programme, 2005. 
[5] A. M. Nzioka, H. U. Hwang, M. G. Kim, C. Z. Yan, C. S. Lee, and Y. J. Kim, "Effect of storage conditions onthe calorific value of municipal solid waste," Waste Management and Research, "2017, in press".

[6] E. L. Morton, L. Szabo, R. Nobis, and S. Alesi, "Method and apparatus for drying wet bio-solids using excess heat from a cement clinker cooler,” US Patent № 20050274067, 2008.

[7] M. Kple, P. Girods, M. Anjorin, B. Fagla, and Y. Rogaume, "Thermal Degradation of Household Solid Waste in the Town of Abomey-Calavi in Benin: Kinetic Study," Waste and Biomass Valorization, vol. 7, no. 1, pp. 59-70, Feb. 2016. doi: 10.1007/s12649-015-9441-9

[8] D. Q. Zhang, P. J. He, and L. M. Shao, "Sorting efficiency and combustion properties of municipal solid waste during bio-drying," Waste Management, vol. 29, pp. 2816-2823, 2009. doi: 10.1016/j.wasman.2009.06.024

[9] F. Jiang, Z. Pan, S. Liu, and H. Wang, "Experimental studies on combustion characteristics of mixed municipal solid waste," Journal of Thermal Science, vol. 12, pp. 367-370, Nov. 2003. doi: 10.1007/s11630-003-0046-4

[10] A. M. Nzioka, M. G. Kim, H. U. Hwang, C. Z. Yan, V. E. Ved, V. P. Meshalkin and Y. J. Kim, "Experimental investigation on the drying of loosely-packed and heterogeneous municipal solid waste," Theoretical Foundations of Chemical Engineering, vol. 50, pp. 414-421, Jul. 2016. doi: 10.1134/S0040579516040448

[11] H. K. Rotich, Y. Zhao and J. Dong, "Municipal solid waste management challenges in developing countries - Kenyan case study," Waste Management, vol. 26, pp. 92-100, 2006. doi: 10.1016/j.wasman.2005.03.007

[12] G. A. Athanasopoulos, "Laboratory Testing of Municipal Solid Waste," in International Symposium on Waste Mechanics "Geotechnical Characterization, Field Measurement, and Laboratory Testing of Municipal Solid Waste", 2008, pp. 195-205. doi: 10.1061/41146(395)7

[13] R. B. Keey, Drying of loose and particulate materials. New York: Hemisphere, 1992.

[14] ASTM E955 - 88(2009)e1 Standard Test Method for Thermal Characteristics of Refuse-Derived Fuel Macrosamples. .

[15] G. V. Ilinykh, "Evaluation of MSW thermotechnical properties based on its composition," PNRPU. Applied Ecology and Urban Development, vol. 3, pp. 125-137, 2013.

[16] M. Heydari, M. Rahman, and R. Gupta, "Kinetic Study and Thermal Decomposition Behavior of Lignite Coal," International Journal of Chemical Engineering, vol. 2015, pp. 1-9, 2015. doi: $10.1061 / 41146(395) 7$

[17] N. A. V. Santos, Z. M. Magriotis, A. A. Saczk, G. T. A. Fássio, and S. S. Vieira, "Kinetic Study of Pyrolysis of Castor Beans ( Ricinus communis L.) Presscake: An Alternative use for Solid Waste Arising from the Biodiesel Production," Energy \& Fuels, vol. 29, pp. 2351-2357, Apr. 2015. doi: 10.1021/ef401933c

[18] H. Hwang, M. Kim, A. Nzioka, Y. Kim, I. Tahir, and C. Yan, "Kinetic characteristics in pyrolysis of RPF with additives," Journal of Wuhan University of Technology, Material Science Edition, vol. 31, pp. 1144-1148, 2016. doi: 10.1007/s11595-016-1503-8

[19] L. L. Baxter, T. R. Miles, T. R. Miles Jr., B. M. Jenkins, T. Milne, D. Dayton, R. W. Bryers and L. L. Oden, "The behavior of inorganic material in biomass-fired power boilers: field and laboratory experiences," Fuel Processing Technology, vol. 54, pp. 47-78, 1998. 